\title{
Perceptions and knowledge of antipsychotics among mental health professionals and patients
}

\author{
Lindah Cahling, ${ }^{1}$ Anders Berntsson, ${ }^{1}$ Gabriella Bröms, ${ }^{2}$ Lars Öhrmalm ${ }^{1,2}$
}

BJPsych Bulletin (2017) 41, 254-259, doi: 10.1192/pb.bp.116.055483

${ }^{1}$ PRIMA, Stockholm, Sweden; ${ }^{2}$ Karolinska Institutet, Stockholm Sweden

Correspondence to Lars Öhrmalm (lars.ohrmalm@prima.se)

First received 5 Oct 2016, final revision 6 Dec 2016, accepted 19 Dec 2016

(C) 2017 The Authors. This is an openaccess article published by the Royal College of Psychiatrists and distributed under the terms of the Creative

Commons Attribution License (http:// creativecommons.org/licenses/by/ 4.0), which permits unrestricted use, distribution, and reproduction in any medium, provided the original work is properly cited.

\begin{abstract}
Aims and method To assess the patients' most influential concerns regarding long-acting injectable antipsychotics (LAls) and mental health professionals' preconceptions about these concerns. For both groups, to assess the level of knowledge about LAls. This cross-sectional study used semi-structured interviews of patients with schizophrenia or schizoaffective disorder $(n=164)$, nurses $(n=43)$ and physicians $(n=20)$.
\end{abstract}

Results The mental health professionals overestimated many of the patients' fears of LAIs, and the expressed fears exceeded the actual experiences of patients already on LAls. Acceptance to switch to LAls was associated with shorter time from diagnosis. Nurses and patients disclosed limited knowledge of antipsychotics.

Clinical implications Physicians and nurses should aim to identify the individual patient's concerns about LAls in the discussion about choice of antipsychotic treatment early in the course of illness.

Declaration of interest L.Ö. has received speaker honoraria from Otsuka Pharma Scandinavia $A B$ and $H$. Lundbeck $A B$, and has accepted travel and hospitality payment from Otsuka Pharma Scandinavia AB.
Adherence to antipsychotic treatment is a major challenge and an important predictor of the outcome in patients with schizophrenia and schizoaffective disorder. ${ }^{1}$ The risks of relapse and admission to hospital increase immediately after discontinuation, even with small treatment gaps. ${ }^{2-5}$ With oral antipsychotics, such gaps often go undetected until relapse - an issue that can be overcome by use of longacting injectable antipsychotics (LAIs). ${ }^{5}$ There is growing evidence that, compared with oral treatment, LAIs reduce the risk of discontinuation, relapse and hospital admission. ${ }^{6}$ Furthermore, owing to superior pharmacokinetics, the use of LAIs is considered to increase the likelihood of finding the lowest effective dose, which subsequently reduces the risk of side-effects. ${ }^{78}$

Despite the identified advantages, LAIs are not used as widely as might be expected. The prescription frequency varies greatly between countries, ${ }^{9}$ indicating that factors other than the patient's attitude influence the utilisation rate. While patients' attitudes towards LAIs become more positive with increased knowledge and experience of the treatment, ${ }^{10}$ clinicians often overestimate patients' resistance against LAIs, anticipating that they will be concerned about the injection procedure. ${ }^{10-12}$ This impedes so-called shared decision-making, an approach with the potential to increase adherence. ${ }^{13}$ Patients are frequently excluded from the discussion about the choice of antipsychotic formulation, ${ }^{14}$ and one reason may be resistance arising from mental health professionals' preconceptions.
We aimed to investigate the specific concerns that affect patients' perceptions of LAIs, and to what extent mental health professionals' preconceptions agree with these perceptions. Furthermore, we aimed to identify knowledge gaps about antipsychotic formulations among both patients and mental health professionals.

\section{Method}

Design

We conducted a cross-sectional study of mental health professionals' and patients' perceptions and knowledge regarding antipsychotic treatment in a psychiatry catchment area in Stockholm, Sweden, operated by PRIMA Adult Psychiatry. Data were collected in semistructured interviews performed by a research nurse (L.C.) at the participant's home clinic between January and October 2015. The participants were enrolled upon giving written informed consent. The study was approved by the regional ethical review board in Stockholm (ref. 2015/47-31).

\section{Participants and setting}

We studied three categories of participants: (a) patients on LAIs; (b) patients on oral treatment; (c) mental health professionals, including physicians and nurses.

We identified all patients with schizophrenia or schizoaffective disorder. Patients with no medical treatment 
or with previous but discontinued LAIs, as well as patients who had been on LAIs $\geqslant 5$ years were excluded. Other exclusion criteria were language barriers (i.e. need of interpreter in consultations), cognitive impairment and severe autism spectrum disorders. We collected information on patients' age, gender, years with diagnosis, marital status, number of children, highest achieved academic degree and occupation. The patients on oral medication were block randomised on diagnosis (schizophrenia/schizoaffective disorder), gender and age to two separate arms. The first group was included in this study to represent those on oral medication, while the second group did not participate and will act as controls in a future intervention study.

All physicians and nurses working in the psychosis sector of PRIMA were asked to participate. We recorded age, gender and extent of experience within the psychiatric field.

\section{Questionnaires}

We conducted semi-structured interviews based on different questionnaires specific to each participant category and designed for the present study. Participants graded their potential concerns with a mark on a continuous $100 \mathrm{~mm}$ scale ranging from 0 ('Does not affect at all') to 100 ('Decisive to decline LAIs'). Potential concerns included in the questionnaire were pain at administration, possible observation time of $3 \mathrm{~h}$, embarrassment at administration, restricted autonomy, feeling of being controlled, being obliged to show up at the clinic regularly, lack of ability to decide when medication is administered, and stigmatisation. The questions were designed to address the participant appropriately, for example, mental health professionals: 'To what extent do you think fear of pain affects the patients' perception?'; patients on oral medication: 'To what extent does fear of pain affect your perception?'; and patients on LAIs: 'To what extent does pain affect your perception?'. The investigated concerns were predefined based on a literature review and clinical experience. ${ }^{10,15,16}$

Questions about knowledge of the differences between LAIs and oral treatment regarding achieved plasma concentration, side-effects and risk of readmission to hospital were identical for all participants and included pre-specified nominal options. In questions regarding clinical approach among mental health professionals, participants were asked to state items freely. Physicians stated their most common reasons for prescribing LAIs, and their strategies to encourage patients to consider LAIs. Furthermore, they were asked to speculate what the patients' key reasons for accepting LAIs are. These answers were assessed using thematic analysis after the study was complete.

Nurses were asked whether they tried to influence patients' and physicians' choice of formulation (yes/no). Patients on oral medication were asked whether they had previously been offered LAIs and whether they knew of the features of being on LAIs. Finally, at the end of the interview, all patients were asked about their perspective on switching formulation (positive/negative).

\section{Statistical analysis}

Anonymised data were analysed using Prism 5.03 for Windows. Sample comparisons were made using Fisher's exact test for categorical variables (gender, positive/ negative towards switching to LAI). The Mann-Whitney $U$-test or Wilcoxon matched-pairs test was used for continuous variables (age, illness duration, mental health professionals' experience and questionnaire responses on a $100 \mathrm{~mm}$ scale), where appropriate.

\section{Results}

\section{Inclusion and exclusion of study participants}

We identified 875 patients in the catchment area with a diagnosis of either schizophrenia or schizoaffective disorder; 341 patients were currently being treated with LAIs (39\%). Of the 875 patients, 302 met our inclusion criteria. Finally, 101 patients on oral treatment and 63 on LAIs participated in the study. The reasons for not participating are presented in Fig. 1. All 21 physicians and 46 nurses working in the psychosis sector of PRIMA were asked to participate; 1 physician and 3 nurses declined owing to lack of time.

\section{Participant characteristics}

There were no statistical differences regarding characteristics between patients on LAIs and patients on oral medication, except that patients on oral medication were more likely to have achieved a higher academic degree (Table 1). The median age of the 20 physicians was 47 years (range 34-69) and 45\% were women. The median number of completed years in the psychiatric field was 6.5 years (range $0-20$ ). The 43 nurses had a median age of 51 years (range 27-67) and $81 \%$ were women. The median length of experience in the psychiatric field was 12 years (range 0-36), and $51 \%$ were specialists in psychiatric care.

\section{Perceptions of LAI antipsychotics}

Comparing patients on oral antipsychotics $v$. patients on LAIs, fears exceeded the actual experiences for all factors examined (Table 2, online Fig. DS1), but fear was only statistically significant for the concerns of being tied to the clinic (62 v. 28, $P=0.018$ ) and loss of decision-making regarding when to take the medicine (45 v. $8, P=0.001$ ). Overall, patients' results tended to be polarised to either end of the $100 \mathrm{~mm}$ scale whereas the mental health professionals' results were more centred in their distribution.

Patients on LAIs were asked to recall their fears before switching from oral treatment. They graded their recalled fears higher than the actual experiences regarding all factors except for observation time (online Table DS1). The differences were small, but reached statistical significance for pain (24 v. 12, $P<0.0001)$, embarrassment (9 v. 7, $P=0.0006)$, reduction in autonomy (13v.10,P=0.0027) and loss of ability to decide when to take the medicine (14 v. 8, $P=0.019)$. Finally, there were no statistically significant differences between the graded fears of patients on oral treatment $v$. recalled fears in patients on LAIs (data not shown).

Mental health professionals overestimated the concerns of orally treated patients regarding feared pain (51 v. 28, $P=0.001$ ), embarrassment (41 v. 12, $P<0.0001$ ), 


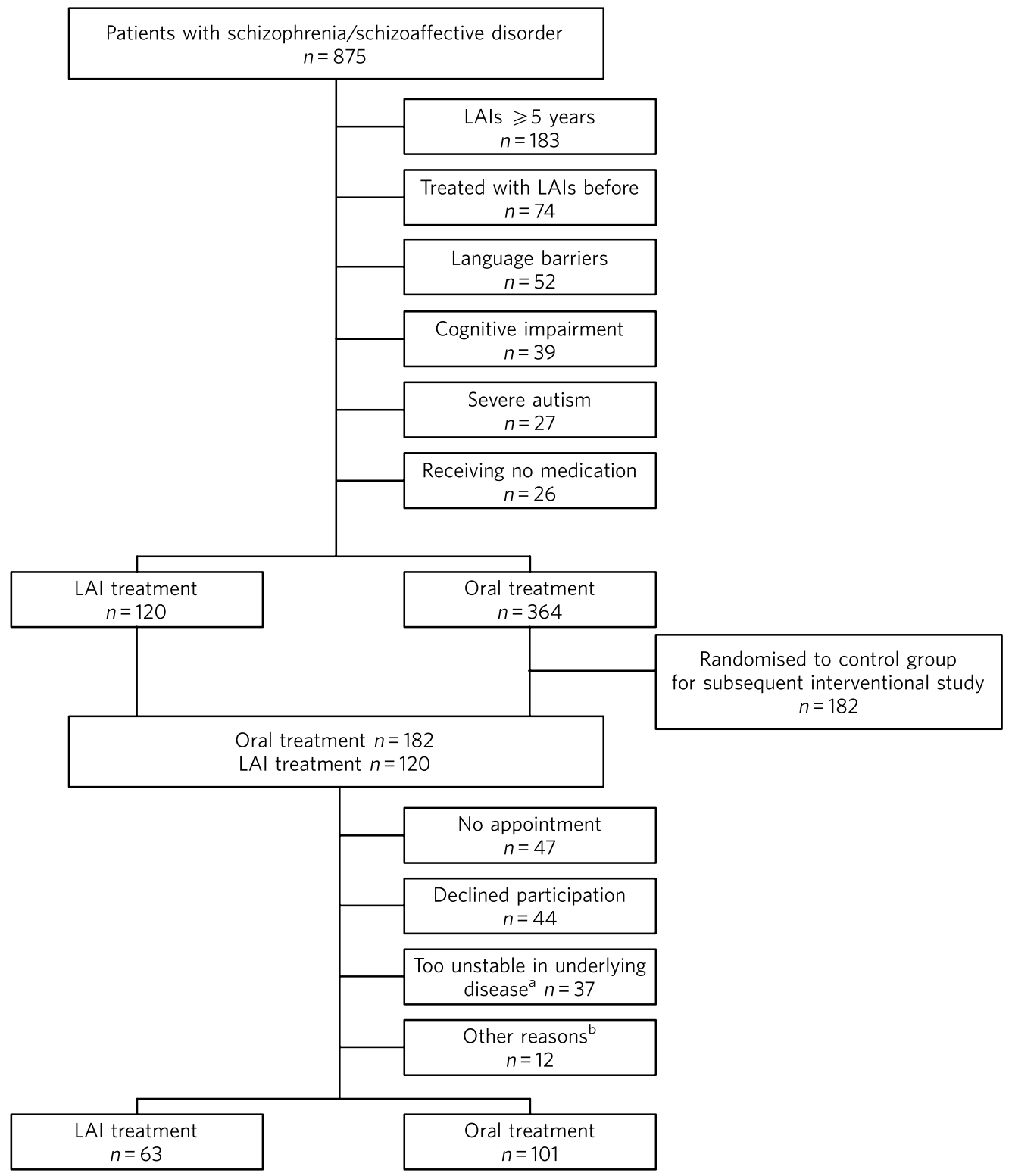

Fig. 1 Flow chart of inclusion in the study. LAI, long-acting injectable antipsychotic. a. As assessed at the time of interview. b. No longer a patient at the clinic, changed formulation before interview, deceased and cognitive impairment.

reduction in autonomy ( $62 v .30, P=0.0025$ ), feeling of being controlled (56 v. 25, $P=0.013$ ), and stigma (51 v. 17, $P=0.0004$; Table 2, online Fig. DS1). Conversely, they underestimated the patients' concerns regarding the $3 \mathrm{~h}$ observation time required after injection of LAI olanzapine (64 v. 89, $P<0.0001$ ).

\section{Knowledge of oral and LAI antipsychotics}

All physicians (100\%) claimed that LAIs are associated with a more stable plasma concentration than oral treatment (Table 3). For nurses, patients on oral treatment and patients on LAIs, the corresponding proportions were $56 \%, 16 \%$ and $22 \%$, respectively.

Of physicians, $90 \%$ stated that LAIs are superior or equal to oral treatment concerning side-effects. For nurses, patients on oral treatment and patients on LAIs, the corresponding proportions were $68 \%, 43 \%$ and $73 \%$, respectively.

All physicians but one (95\%) and $86 \%$ of nurses claimed that LAIs reduce the risk of readmission to hospital, while $21 \%$ of patients with oral treatment and $36 \%$ of patients on LAIs claimed LAIs to be superior in this matter.

\section{Clinical approach to LAls among mental health professionals}

Poor adherence, limited insight and multiple relapses were the most common reasons for prescribing LAIs, mentioned by $80 \%$ of physicians. However, one-fourth considered LAIs an option even early in the disease course. Their strategies to encourage patients to consider LAIs were to inform them about the advantages of the formulation (65\%) and about the risks and consequences of treatment discontinuation 


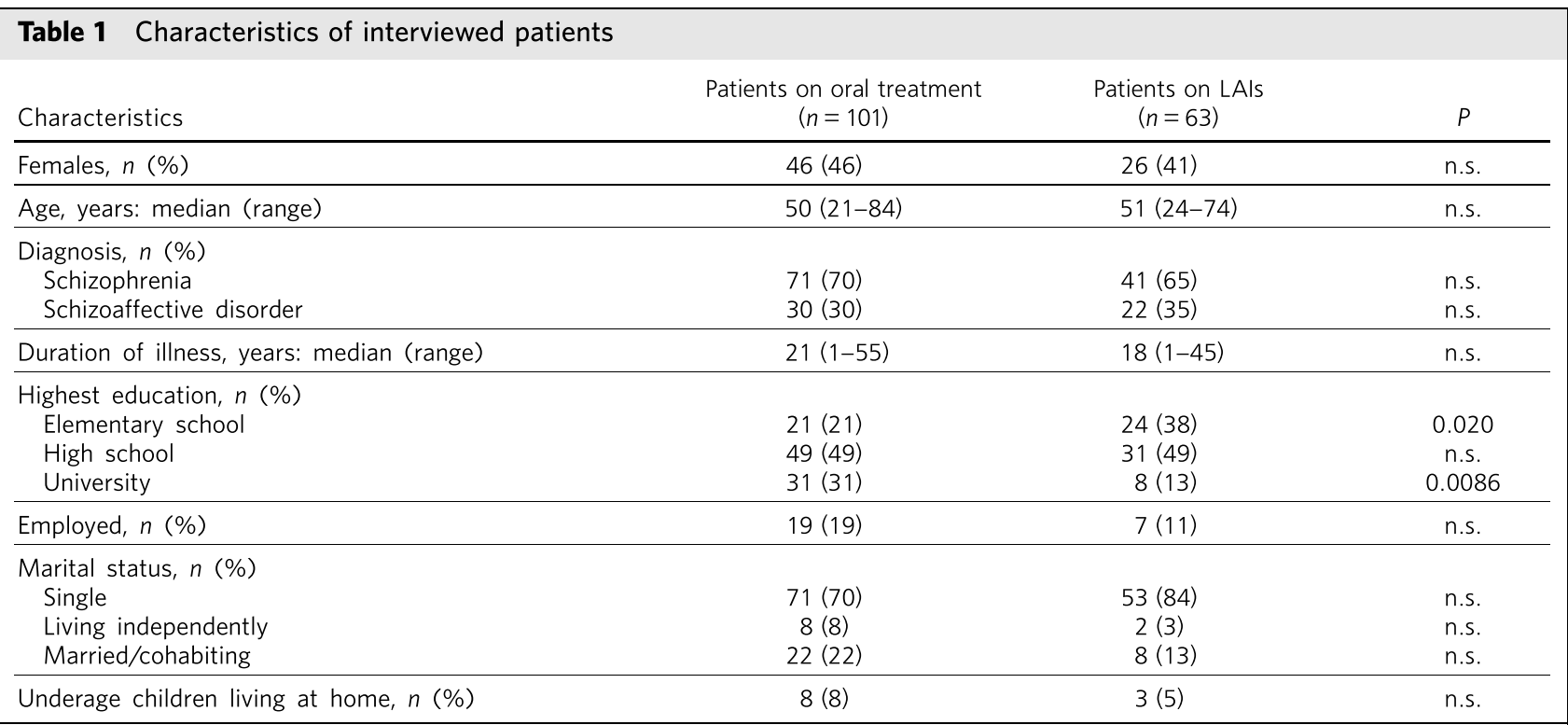

LAls, long-acting injectable antipsychotics; n.s., not significant.

\begin{tabular}{|c|c|c|c|c|c|}
\hline Factors & $\begin{array}{l}\text { Mental health } \\
\text { professionals } \\
\quad(n=63)\end{array}$ & $\begin{array}{l}\text { Patients on oral } \\
\text { treatment } \\
(n=101)\end{array}$ & $P$ & $\begin{array}{l}\text { Patients on LAls } \\
\quad(n=63)\end{array}$ & $P^{a}$ \\
\hline Pain at the injection site & $50.5(11-95)$ & $28(0-100)$ & 0.001 & $12(0-100)$ & 0.21 \\
\hline Being regularly tied to a clinic & $49(5-98)$ & $62(0-100)$ & 0.24 & $28(0-99)$ & 0.018 \\
\hline $\begin{array}{l}\text { Observation time at the clinic after one } \\
\text { certain type of } \mathrm{LAl}^{\mathrm{b}}\end{array}$ & $64(4-98)$ & $89(0-100)$ & $<0.0001$ & $67(3-98)$ & 0.23 \\
\hline Embarrassment of having an injection & $41(1-93)$ & $12(0-98)$ & $<0.0001$ & $7(0-100)$ & 0.11 \\
\hline Reduction in autonomy & $62(5-93)$ & $30(0-98)$ & 0.0025 & $10(0-100)$ & 0.18 \\
\hline $\begin{array}{l}\text { Loss of ability to decide when to take the } \\
\text { medication }\end{array}$ & $56(4-95)$ & $45(0-100)$ & 0.13 & $8(0-98)$ & 0.001 \\
\hline Feeling of being controlled & $56(3-94)$ & $25(0-100)$ & 0.013 & $13(0-100)$ & 0.58 \\
\hline Perceptions of stigma of being on LAI & $51(4-88)$ & $17(0-100)$ & 0.0004 & $11(0-100)$ & 0.63 \\
\hline
\end{tabular}

The questions were presented orally and adapted based on the participant category, i.e. mental health professionals, patients on oral treatment and patients on LAls. a. Patients on oral treatment $v$. patients on LAls.

b. Only the 7 patients on long-acting injectable olanzapine who had experienced a $3 \mathrm{~h}$ observation time were included.

(40\%). Exploring patients' fears was a strategy mentioned by $20 \%$ of physicians.

Half of physicians believed that not having to remember to take pills was the key reason for patients to accept LAIs. Other factors mentioned were good insight $(40 \%)$ and that LAIs are associated with lower frequency of relapse (20\%).

Of nurses, $31(72 \%)$ replied that they actively tried to influence the patients' attitude towards one or the other formulation, and $29(67 \%)$ actively tried to influence the physician's decision.

\section{Patients' perspective on switching}

Almost half of the patients on oral treatment (41\%) declared that they had little or no knowledge of LAIs. At the end of the interview, they were asked whether they would switch to LAIs if offered by their treating physician. While 78 (77\%) said no and three (3\%) could not decide, $20(20 \%)$ declared that they would agree to switch if offered such an option. The patients willing to switch had fewer years since diagnosis than those who were reluctant (12 v. 24, $P=0.0013$; online Fig. DS2). Furthermore, the proportion of women was higher in the positive group (75\% v. 44\%, odds ratio $(\mathrm{OR})=3.9, P=0.023)$. They considered pain $(7 v$. 40, $P=0.020)$, being tied to the clinic (26v. 70, $P=0.017)$, reduction in autonomy ( $9 v .30, P=0.034)$ and stigma $(6 v$. 27, $P=0.035$ ) to be less important issues than did the patients who were reluctant to switch to LAIs.

A total of 21 (33\%) patients on LAIs would switch to oral treatment if they were offered it, 1 (1.6\%) could not decide and $41(65 \%)$ preferred to continue with LAIs. There were no statistically significant differences between patients who were positive $v$. patients who were negative about switching formulation with regard to age, number of years with diagnosis or gender. Those who opted to stay on LAIs 
Table 3 Mental health professionals' and patients' knowledge about oral $v$. long-acting injectable antipsychotics (LAls) regarding plasma concentration, side-effects and frequency of readmission to hospital

\begin{tabular}{|c|c|c|c|c|}
\hline Topic & $\begin{array}{l}\text { Physicians } \\
(n=20)\end{array}$ & $\begin{array}{l}\text { Nurses } \\
(n=43)\end{array}$ & $\begin{array}{l}\text { Patients on oral treatment } \\
\qquad(n=101)\end{array}$ & $\begin{array}{c}\text { Patients on LAls } \\
\quad(n=63)\end{array}$ \\
\hline \multicolumn{5}{|l|}{ Plasma concentration, $n(\%)$} \\
\hline Lower/more stable with LAls & $20(100)$ & $24(56)$ & $16(16)$ & $14(22)$ \\
\hline Equal & $0(0)$ & $11(26)$ & $23(23)$ & $20(32)$ \\
\hline Lower/more stable with oral & $0(0)$ & $4(9)$ & $41(41)$ & $20(32)$ \\
\hline Don't know & $0(0)$ & $4(9)$ & $21(21)$ & $9(14)$ \\
\hline \multicolumn{5}{|l|}{ Side-effects, $n(\%)$} \\
\hline Less with LAls & $15(75)$ & $12(28)$ & $18(18)$ & $27(43)$ \\
\hline Equal & $3(15)$ & $17(40)$ & $25(25)$ & $19(30)$ \\
\hline Less with oral & $1(5)$ & $11(26)$ & $45(45)$ & $11(17)$ \\
\hline Don't know & $1(5)$ & $3(7)$ & $13(13)$ & $6(10)$ \\
\hline \multicolumn{5}{|l|}{ Risk of rehospitalisation, $n(\%)$} \\
\hline Less with LAls & $19(95)$ & $37(86)$ & $21(21)$ & $23(36)$ \\
\hline Equal & $0(0)$ & $3(7)$ & $40(40)$ & $20(32)$ \\
\hline Less with oral & $1(5)$ & $2(5)$ & $15(15)$ & $5(8)$ \\
\hline Don't know & $0(0)$ & $1(2)$ & $25(25)$ & $15(24)$ \\
\hline
\end{tabular}

Eligible answers were presented as pre-specified nominal options.

were less concerned with the lack of autonomy ( $7 v .40$, $P=0.015)$ and the feeling of being controlled (9 v. 50, $P=0.0011)$. They also gave more correct answers regarding differences in side-effects between oral formulations and LAIs $(85 \%$ v. $52 \%$, OR $=5.3, P=0.012)$

\section{Discussion}

In this study, we found that patients' concerns with LAIs were minor except when considering observation time and being tied to the clinic, and that there was a mismatch in the assessment of specific concerns between the patients and the mental health professionals. We identified important knowledge gaps among patients and nurses. As many as one-fifth of the patients on oral medications were willing to switch to LAIs; these potential switchers were more recently diagnosed than those who were reluctant.

The patients on oral treatment were most concerned about observation time post-injection and about being tied to the clinic when asked about LAIs. This indicates that they valued their time and that practical issues surpassed in significance emotional ones such as stigma, a feeling of being controlled and embarrassment. All fears expressed by patients on oral treatment exceeded the actual experiences of patients on LAIs. This could be a result of selection bias, in that patients on LAIs were less concerned even before accepting LAI treatment. However, since patients on LAIs were speaking from experience, this difference may also reflect that these issues had a lower impact than expected once the patients had been started on LAIs. That the recalled concerns pre-LAIs were similar to the levels of concern among those still on oral treatment also supports this hypothesis.

Mental health professionals tended to answer questions by placing the indicator centrally on the $100 \mathrm{~mm}$ scale, which may reflect uncertainty as they were just estimating the patients' experiences. The patients' answers, on the other hand, were polarised, indicating that their opinions were more set. Patients also graded some factors distinctly low and others distinctly high. In light of this, physicians should be encouraged to learn more about the individual patient's concerns. Only $20 \%$ of physicians reported that they used this strategy when discussing treatment regimens.

According to previous studies, physicians' knowledge regarding antipsychotic formulations varies. ${ }^{16,17}$ Physicians in the current study showed very good knowledge. However, a significant proportion of the interviewed nurses had knowledge gaps concerning some of the advantages of LAIs. This could have a negative impact on the patient's attitude towards LAIs, especially as the majority of nurses claimed that they actively tried to influence both doctors and patients in the discussion on treatment choices. Patients already on LAIs had significantly better knowledge about the reduced side-effects with LAIs than patients on oral treatment. This most likely reflects their own experiences. It could also be an effect of information provided by mental health professionals - information many patients on oral treatment reported as lacking. This is of concern, as we know that patients' attitudes towards LAIs are likely to become more positive with increased knowledge and experience of the treatment. ${ }^{10}$ The physicians' observed reluctance to bring up the topic may be due to their anticipation that the patients are unlikely to accept the offered LAI. However, keeping the patients uninformed makes shared decision-making impossible. ${ }^{15}$

The majority of the patients on LAIs chose to keep this formulation and as many as $20 \%$ of the patients on oral treatment were willing to use LAIs. This is in line with a previous study in which $16 \%$ were positive towards a formulation switch. ${ }^{14}$ This also supports the hypothesis that the use of LAIs could be limited by factors other than rejection by the patients. ${ }^{12}$ Some physicians claimed that they offered LAIs early in the disease course, but their most common reasons for prescribing LAIs were poor adherence to oral medication and recurring relapses. Previous studies also report non-adherence ${ }^{16,17}$ and multiple relapses ${ }^{17}$ as key criteria for prescribing LAIs. This may be unfortunate as longer illness duration was associated with being reluctant to switch. Instead, this motivates a discussion of LAIs early on in the course of illness, especially as there is cumulative 
evidence that the use of LAIs as early as after the first admission to hospital decreases the risk of treatment discontinuation, relapse and readmission., ${ }^{4,5,18}$

\section{Limitations}

Our study has several limitations. Not all patients in the targeted study population were included, and some patients could not be reached or were not present to complete the questionnaire. Some were only scheduled for visits once per calendar year, while the study was limited to 10 months. It is possible that patients were either too ill to present themselves or were stable enough to postpone yearly visits. The patients on LAIs were asked to declare their perceptions prior to starting on LAIs, which introduced recall bias. However, we excluded all patients on LAIs $\geqslant 5$ years, reducing the effect of this bias. Finally, patients on LAIs are indisputably a selection of patients who have once accepted that formulation. However, the lack of significant differences between the graded fears of patients on oral treatment compared with recalled fears in patients with LAIs may indicate that this selection bias is of minor concern. A strength of this study was that all interviews were performed by the same person (L.C.), securing consistency across interviews.

\section{Clinical implications}

In conclusion, physicians should aim to set aside their own preconceptions and instead make time to identify the individual's specific fears regarding LAIs, preferably early in the course of the illness. In addition, there is room for improvement regarding patients' knowledge of antipsychotic formulations. Adequate education would be of value to strengthen nurses' knowledge about LAIs. Finally, there is room for improvement regarding patients' knowledge of antipsychotic formulations.

\section{Funding}

This work was supported by $H$. Lundbeck $A B$ and Otsuka Pharma Scandinavia $A B$.

\section{About the authors}

Lindah Cahling specialist nurse, and Anders Berntsson psychiatrist, head of clinic, PRIMA Child and Adult Psychiatry, Stockholm, Sweden; Gabriella Bröms, MD, PhD, Department of Medicine, Solna, Karolinska Institutet, Stockholm, Sweden; Lars Öhrmalm, MD, assistant professor, PRIMA Child and Adult Psychiatry, and Department of Medicine, Solna, Karolinska Institutet, Stockholm, Sweden.

\section{References}

1 Weiden PJ. Understanding and addressing adherence issues in schizophrenia: from theory to practice. J Clin Psychiatry 2007; 68 (suppl 14): 14-9.
2 Weiden PJ, Kozma C, Grogg A, Locklear J. Partial compliance and risk of rehospitalization among California Medicaid patients with schizophrenia. Psychiatr Serv 2004; 55: 886-91.

3 Subotnik KL, Nuechterlein KH, Ventura J, Gitlin MJ, Marder S, Mintz J, et al. Risperidone nonadherence and return of positive symptoms in the early course of schizophrenia. Am J Psychiatry 2011; 168: 286-92.

4 Heres S, Lambert M, Vauth R. Treatment of early episode in patients with schizophrenia: the role of long acting antipsychotics. Eur Psychiatry 2014; 29 (suppl 2): 1409-13

5 Marcus SC, Zummo J, Pettit AR, Stoddard J, Doshi JA. Antipsychotic adherence and rehospitalization in schizophrenia patients receiving oral versus long-acting injectable antipsychotics following hospital discharge. J Manag Care Spec Pharm 2015; 21: 754-68.

6 Kirson NY, Weiden PJ, Yermakov S, Huang W, Samuelson T, Offord SJ, et al. Efficacy and effectiveness of depot versus oral antipsychotics in schizophrenia: synthesizing results across different research designs. J Clin Psychiatry 2013; 74: 568-75.

7 Dencker SJ. The risk/benefit ratio of depot neuroleptics: a Scandinavian perspective. J Clin Psychiatry 1984; 45: 22-7.

8 Gerlach J. Depot neuroleptics in relapse prevention: advantages and disadvantages. Int Clin Psychopharmacol 1995; 9 (suppl 5): 17-20.

9 Agid O, Foussias G, Remington G. Long-acting injectable antipsychotics in the treatment of schizophrenia: their role in relapse prevention. Expert Opin Pharmacother 2010; 11: 2301-17.

10 Waddell L, Taylor M. Attitudes of patients and mental health staff to antipsychotic long-acting injections: systematic review. Br J Psychiatry 2009; suppl. 52: S43-50.

11 Patel MX, De Zoysa N, Bernadt M, David A. Depot and oral antipsychotics: patient preferences and attitudes are not the same thing. J Psychopharmacol 2009; 23: 789-96.

12 Weiden PJ, Roma RS, Velligan DI, Alphs L, DiChiara M, Davidson B. The challenge of offering long-acting antipsychotic therapies: a preliminary discourse analysis of psychiatrist recommendations for injectable therapy to patients with schizophrenia. J Clin Psychiatry 2015; 76 684-90.

13 Beitinger R, Kissling W, Hamann J. Trends and perspectives of shared decision-making in schizophrenia and related disorders. Curr Opin Psychiatry 2014; 27: 222-9.

14 Potkin S, Bera R, Zubek D, Lau G. Patient and prescriber perspectives on long-acting injectable (LAI) antipsychotics and analysis of in-office discussion regarding LAI treatment for schizophrenia. BMC Psychiatry 2013; 13: 261.

15 Das AK, Malik A, Haddad PM. A qualitative study of the attitudes of patients in an early intervention service towards antipsychotic longacting injections. Ther Adv Psychopharmacol 2014; 4: 179-85.

16 Patel MX, Haddad PM, Chaudhry IB, McLoughlin S, Husain N, David AS. Psychiatrists' use, knowledge and attitudes to first- and secondgeneration antipsychotic long-acting injections: comparisons over 5 years. J Psychopharmacol 2010; 24: 1473-82.

17 James BO, Omoaregba JO, Okonoda KM, Otefe EU, Patel MX. The knowledge and attitudes of psychiatrists towards antipsychotic long acting injections in Nigeria. Ther Adv Psychopharmacol 2012; 2: 169-77.

18 Subotnik KL, Casaus LR, Ventura J, Luo JS, Helleman GS, GretchenDoorly $\mathrm{D}$, et al. Long-acting injectable risperidone for relapse prevention and control of breakthrough symptoms after a recent first episode of schizophrenia. A randomized clinical trial. JAMA Psychiatry 2015; 72 $822-9$.

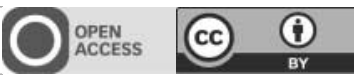




\section{Online data supplement}

Table DS1. Recalled fears among patients on long-acting injectables (LAIs) prior to switch from oral treatment and subsequent actual experiences of LAIs

\begin{tabular}{|c|c|c|c|}
\hline Affecting factors, median (range) & $\begin{array}{l}\text { Recalled fears } \\
\quad(n=63)\end{array}$ & $\begin{array}{c}\text { Actual } \\
\text { experiences } \\
(n=63)\end{array}$ & $P$ \\
\hline Pain at the injection site & $24(0-98)$ & $12(0-100)$ & $<0.0001$ \\
\hline Being regularly tied to a clinic & $42(0-99)$ & $28(0-99)$ & 0.083 \\
\hline $\begin{array}{l}\text { Observation time at the clinic after one } \\
\text { certain type of } \mathrm{LAI}^{\dagger}\end{array}$ & $26(2-96)$ & $74(3-98)$ & 0.87 \\
\hline Embarrassment of having an injection & $9(0-100)$ & $7(0-100)$ & 0.0006 \\
\hline Reduction in autonomy & $13(1-100)$ & $10(0-100)$ & 0.0027 \\
\hline $\begin{array}{l}\text { Loss of possibility to decide when to } \\
\text { take the medication }\end{array}$ & $14(0-100)$ & $8(0-98)$ & 0.019 \\
\hline Feeling of being controlled & $16(0-98)$ & $13(0-100)$ & 0.015 \\
\hline Perceptions of stigma being on LAI & $15(1-100)$ & $11(0-100)$ & 0.0007 \\
\hline
\end{tabular}




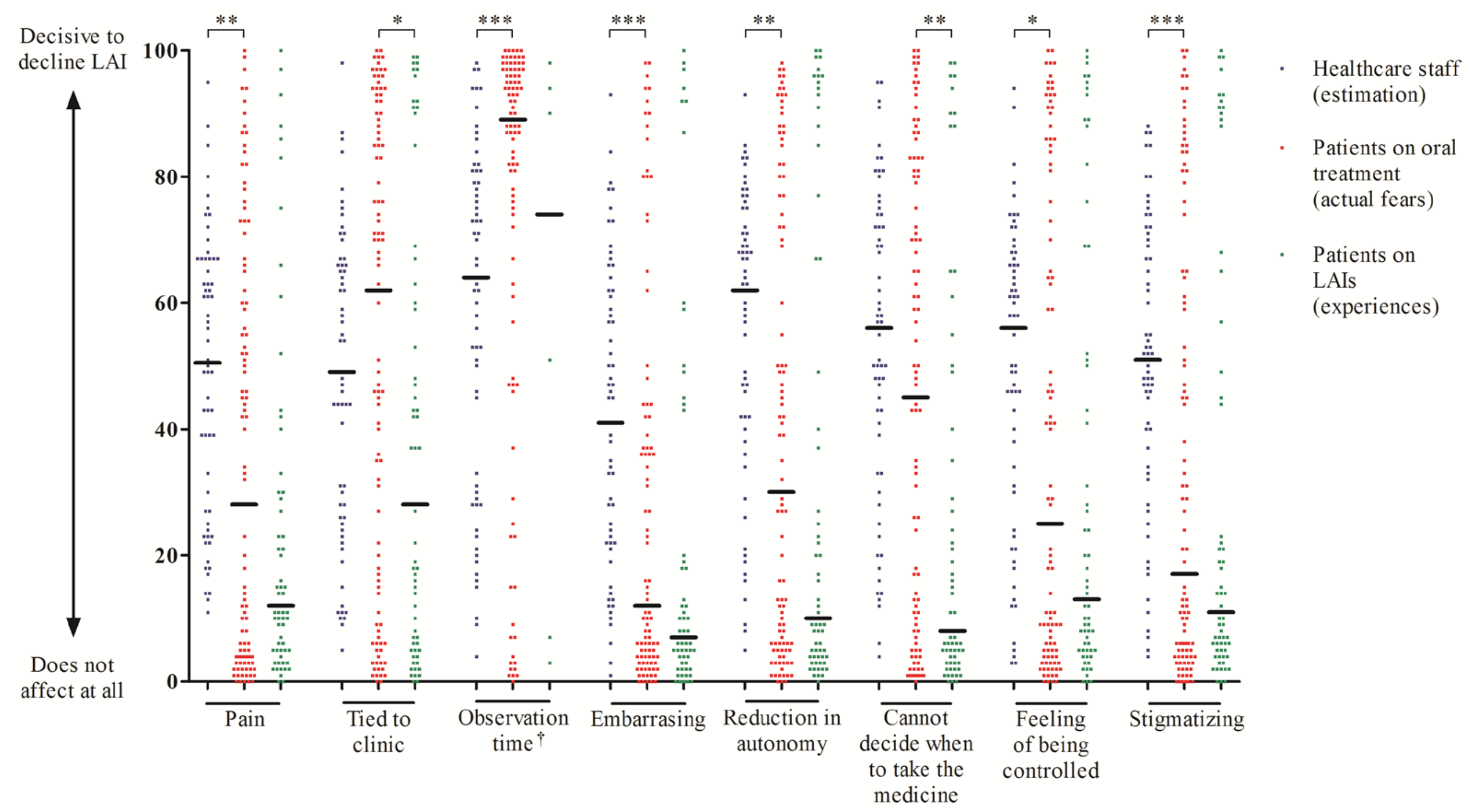

Fig. DS1 Estimated and actual fears as well as experienced factors affecting the decision to decline long-acting injectable antipsychotics. 
Questions in full length are presented in Supplementary Table 1. ${ }^{*} P<0.05,{ }^{*} P<0.01,{ }^{* * *} P<0.001 .{ }^{\dagger} 7$ patients on long-acting injectable olanzapine who had experienced a 3-hour observation time.

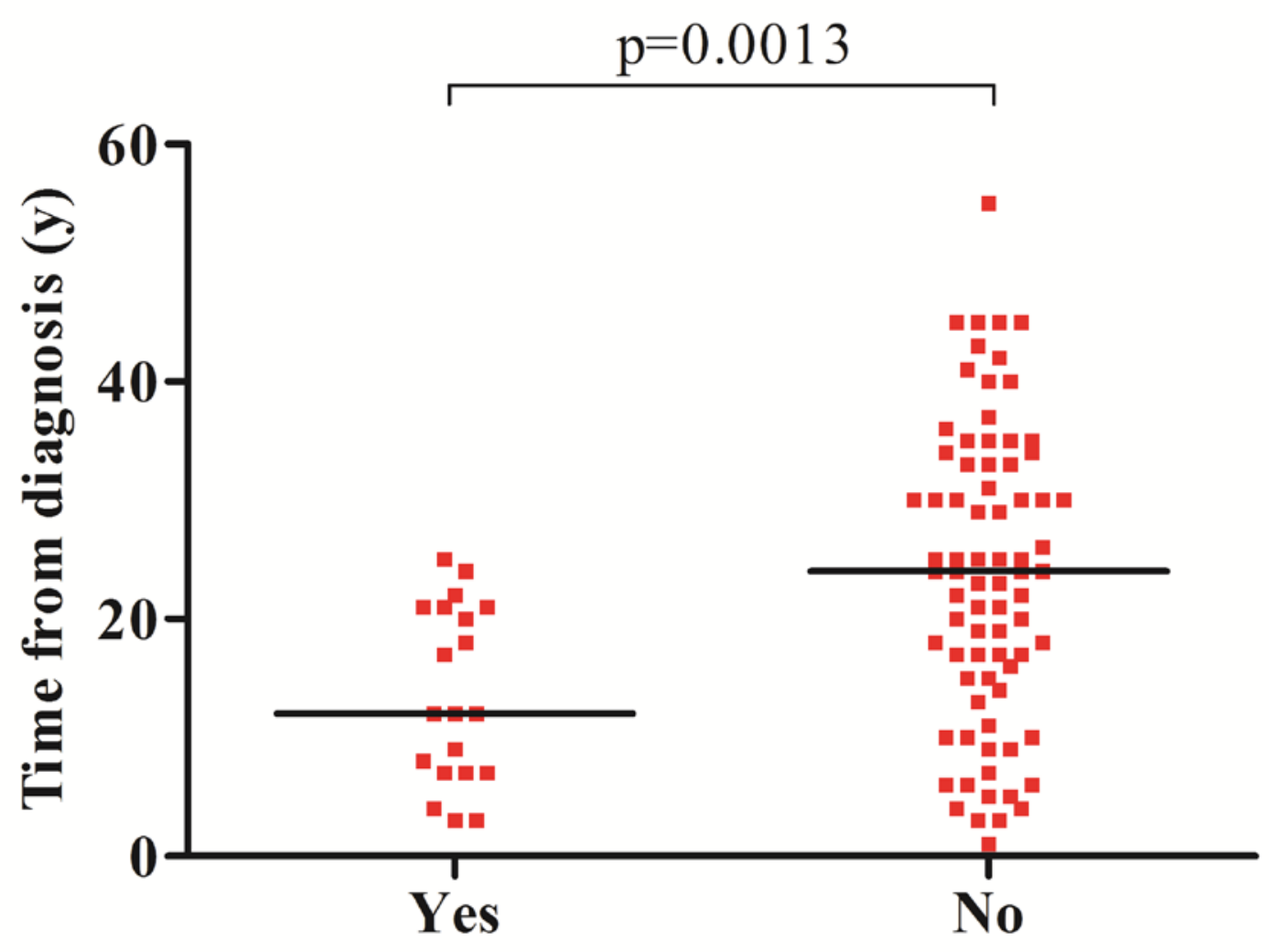

Fig. DS2 Patients on oral treatment that are positive to switch to LAIs if they were offered by their physician $(n=20)$ are compared with those who declined $(n=78)$ regarding number of years since diagnosis. 
PB/2016/055483, doi: 10.1192/pb.bp.116.055483 


\section{BJPsych}

Bu

\section{Perceptions and knowledge of antipsychotics among mental health professionals and patients \\ Lindah Cahling, Anders Berntsson, Gabriella Bröms and Lars Öhrmalm BJPsych Bull 2017, 41:254-259. \\ Access the most recent version at DOI: 10.1192/pb.bp.116.055483}

\begin{tabular}{|c|c|}
\hline $\begin{array}{l}\text { Supplementary } \\
\text { Material }\end{array}$ & $\begin{array}{l}\text { Supplementary material can be found at: } \\
\text { http://pb.rcpsych.org/content/suppl/2017/06/12/pb.bp.116.055483.DC1 }\end{array}$ \\
\hline References & $\begin{array}{l}\text { This article cites } 17 \text { articles, } 0 \text { of which you can access for free at: } \\
\text { http://pb.rcpsych.org/content/41/5/254\#BIBL }\end{array}$ \\
\hline $\begin{array}{r}\text { Reprints/ } \\
\text { permissions }\end{array}$ & $\begin{array}{l}\text { To obtain reprints or permission to reproduce material from this paper, please } \\
\text { write to permissions@rcpsych.ac.uk }\end{array}$ \\
\hline $\begin{array}{l}\text { You can respond } \\
\text { to this article at }\end{array}$ & /letters/submit/pbrcpsych;41/5/254 \\
\hline $\begin{array}{c}\text { Downloaded } \\
\text { from }\end{array}$ & $\begin{array}{l}\text { http://pb.rcpsych.org/ on November 16, } 2017 \\
\text { Published by The Royal College of Psychiatrists }\end{array}$ \\
\hline
\end{tabular}

